\title{
In vivo assessment of canine muscle adiposity by real time ultrasonography and image analysis
}

\author{
Rita Payan-Carreira ${ }^{1 *}$, Luis Martins², Sónia Miranda1,2,3 ${ }^{1,}$ Pedro O Pinto ${ }^{2,3}$, Severiano R Silva ${ }^{1}$ \\ From Animal Obesity - causes, consequences and comparative aspects \\ Uppsala, Sweden. 14-16 June 2015
}

\section{Introduction}

Obesity in dogs is a growing concern. Different surveys report a recent increase in dog obesity, their estimates ranging from 22 to over $50 \%$. Surveillance of dog body condition score (BCS) is a routine practice but it is not sensitive enough. Ultrasound (US) assessment of body fat deposits was previously used in different species to predict adiposity, and shows several advantages, like its relative low cost, portability, and great repeatability. In human, intramuscular fat was associated with obesity systemic effects.

\section{Objectives}

This study aimed to assess the relationship between BCS and intramuscular fat infiltration (IMF) in healthy dogs.

\section{Material and methods}

Twenty-eight dogs were used, with different sizes (nain4; small-10; medium-14), weights (5.2-33.0 kg) and BCS (2-4 in a 5 points scale). US images were collected from non-sedated dogs in right lateral recumbency and were analysed in Image J. The rough surface and small size of IMF flecks within the muscle cause sound waves to scatter, which produced hyperechoic speckles on the US image. An IMF threshold value is determined. Thereafter a region of interest is converted into an 8-bit grey scale and the threshold applied. The IMF-related mask was overlaid onto the image and numerical data extracted. Relationships between IMF (dependent) and BCS (independent) were established by simple and polynomial regressions.

\footnotetext{
* Correspondence: rtpayan@gmail.com

${ }^{1}$ Animal and Veterinary Research Center, CECAV, Universidade de Trás-osMontes e Alto Douro, Vila Real, Portugal

Full list of author information is available at the end of the article
}

\section{Results}

The coefficient of determination in polynomial equations was always higher than or equal to that of linear equations ( $\mathrm{r} 2$ between $0.197, \mathrm{p}=0.018$, and $0.811, \mathrm{p}<0.001$ ).

\section{Conclusion}

This study showed that pertinent information about dog IMF depot might be obtained from US image analysis.

\section{Authors' details \\ ${ }^{1}$ Animal and Veterinary Research Center, CECAV, Universidade de Trás-os- Montes e Alto Douro, Vila Real, Portugal. 'Escola Universitária Vasco da Gama, Coimbra, Portugal. ${ }^{3}$ Hospital Veterinário do Baixo Vouga, Águeda, Portugal.}

Published: 25 September 2015

doi:10.1186/1751-0147-57-S1-O2

Cite this article as: Payan-Carreira et al:: In vivo assessment of canine muscle adiposity by real time ultrasonography and image analysis. Acta Veterinaria Scandinavica 2015 57(Suppl 1):O2.

Submit your next manuscript to BioMed Central and take full advantage of:

- Convenient online submission

- Thorough peer review

- No space constraints or color figure charges

- Immediate publication on acceptance

- Inclusion in PubMed, CAS, Scopus and Google Scholar

- Research which is freely available for redistribution 